\title{
Congenital Long QT Syndrome Type 8 Characterized by Fetal Onset of Bradycardia and 2:1 Atrioventricular Block
}

Donghoon Joo, MD, Hyoung Doo Lee, MD, PhD, Taehong Kim, MD, PhD, Hoon Ko, MD, and Joung-Hee Byun, $\mathrm{MD}$

Department of Pediatrics, Pusan National University Children's Hospital, Yangsan, Korea

\section{ABSTRACT}

An important, albeit rare, cause of fetal bradycardia is long QT syndrome (LQTS). Congenital LQTS is an ion channelopathy caused by mutations in genes encoding cardiac ion channel proteins. Fetal onset of LQTS imposes high risk of life-threatening tachyarrhythmias and sudden cardiac death. Here, we report the case of a female newborn with fetal onset of bradycardia and a 2:1 atrioventricular (AV) block. After birth, a 12-lead electrocardiogram (ECG) revealed bradycardia with QT prolongation of a corrected QT (QTc) interval of $680 \mathrm{~ms}$ and pseudo 2:1 AV block. Genetic testing identified a heterozygous Gly402Ser (c.1204G>A) mutation in CACNA1C, confirming the diagnosis of LQTS type 8 (LQT8). The patient received propranolol at a daily dose of $2 \mathrm{mg} / \mathrm{kg}$. Mexiletine was subsequently administered owing to the sustained prolongation of the QT interval and pseudo 2:1 AV block. One week after mexiletine inception, the ECG still showed QT interval prolongation (QTc, $632 \mathrm{~ms}$ ), but no AV block was observed. There were no life-threatening tachyarrhythmias in a follow-up period of 13 months.

Key Words: Long QT syndrome; Atrioventricular block; Prenatal diagnosis; Infant

\section{INTRODUCTION}

Fetal bradycardia is characterized by a ventricular heart rate slower than 100 beats per minute (bpm), mainly owing to atrioventricular (AV) block. The most common causes of fetal bradycardia are congenital heart diseases. The other important, albeit rare, cause is long QT syndrome (LQTS) ${ }^{1}$. Fetal echocardiography is a useful diagnostic modality for prenatal arrhythmia, and an M-mode trace of ventricular and atrial motion demonstrates fetal cardiac rhythm ${ }^{2)}$.

LQTS is a primary cardiac channelopathy, characterized by QT prolongation, syncope, and ventricular arrhythmias poses a high risk of sudden cardiac death. LQTS is classified into 17 types, and its causative genes are inherited in an autosomal-dominant or autosomalrecessive form. Mutations of $K C N Q 1, K C N H 2$, and $S C N 5 A$ are the major causes of LQTS ${ }^{3,4)}$.
Received: 5 October 2020

Revised: 20 October 2020

Accepted: 22 October 2020

Correspondence to: Joung-Hee Byun, MD

Department of Pediatrics, Pusan National University Children's Hospital, 20 Geumo-ro, Mulgeum-eup, Yangsan 50612, Korea

Tel: +82-55-360-2180

Fax: +82-55-360-2181

E-mail: africa3217@naver.com

\section{Copyright(c)}

By Korean Society of Neonatology.

All right reserved.

This is an Open-Access article distributed under the terms of the Creative Commons Attribution Non-Commercial License (http:// creativecommons.org/licenses/by-nc/4.0), which permits unrestricted non-commercial use, distribution, and reproduction in any medium, provided the original work is properly cited. 
In 2004, a G406R mutation in calcium voltage-gated channel subunit al (CACNA1C) gene was identified in patients with Timothy syndrome (TS) or LQTS type 8(LQT8), a specific subtype of LQTS. LQT8 and TS are related to mutations in CACNA1C. TS is a multisystem syndrome associated with QT prolongation and ventricular tachyarrhythmias ${ }^{5)}$. Recent advances in genetic analyses have encouraged studies concerning LQT8 ${ }^{6-8)}$.

\section{CASE REPORT}

A38-year-old woman (gravida 4, para 2) at 34 weeks of gestation was referred to our hospital because of fetal bradycardia. The fetal M-mode echocardiogram revealed bradycardia and a 2:1 AV block with an atrial rate marching out regularly at $132 \mathrm{bpm}$, and a ventricular rate of $63 \mathrm{bpm}$ (Figure 1). The fetal cardiac structures were normal and the ventricular function was good. She had no medication history during pregnancy or family history suggestive of arrhythmia. Her laboratory tests, including thyroid function tests, electrolytes, and 25-OH vitamin D levels, were all normal.

The infant was delivered by elective cesarean section at $38^{+2}$ weeks of gestation and had a birth weight of 2,680 g. The Apgar scores were 8 at 1 minute and 9 at 5 minutes. The 12-lead electrocardiogram (ECG) performed immediately after birth revealed bradycardia, a heart rate of $68 \mathrm{bpm}$ with QT prolongation of a corrected QT (QTc) interval of $680 \mathrm{~ms}$ (using Bazett formula), and a pseudo 2:1 AV block (Figure 2). She had no anomalies upon phy sical examination and echocardiography.

The baby received propranolol at a daily dose of $2 \mathrm{mg} / \mathrm{kg}$. On the 9 th hospital day, mexiletine $(6 \mathrm{mg} / \mathrm{kg} /$ day $)$ was orally admini-

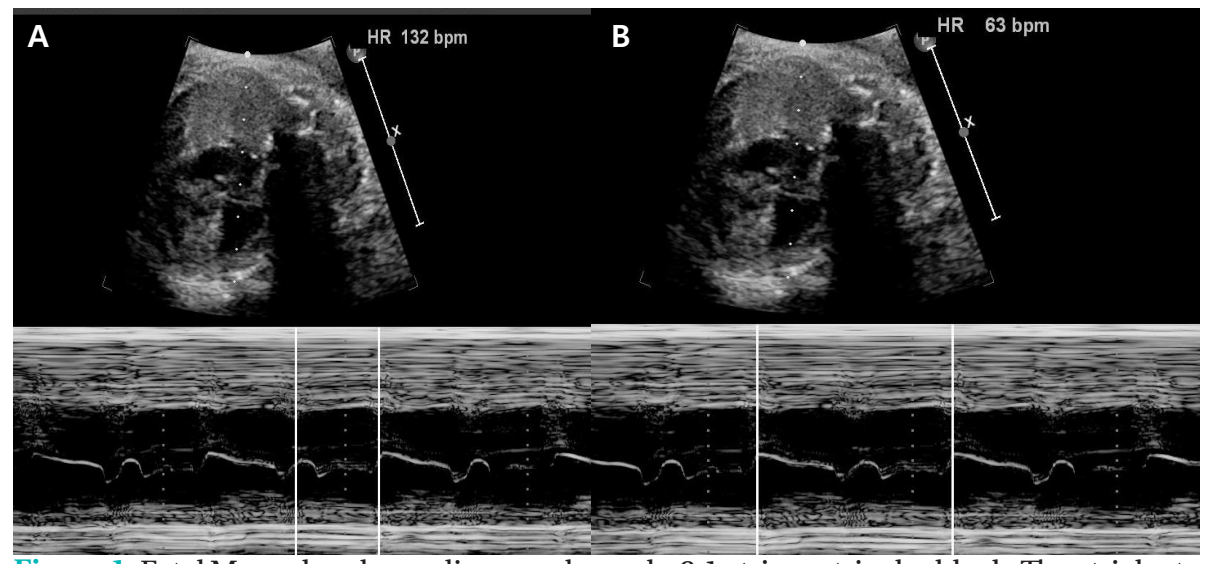

Figure 1. Fetal M-mode echocardiogram showed a 2:1 atrioventricular block. The atrial rate (A) was $132 \mathrm{bpm}$ and the ventricular rate (B) was $63 \mathrm{bpm}$.

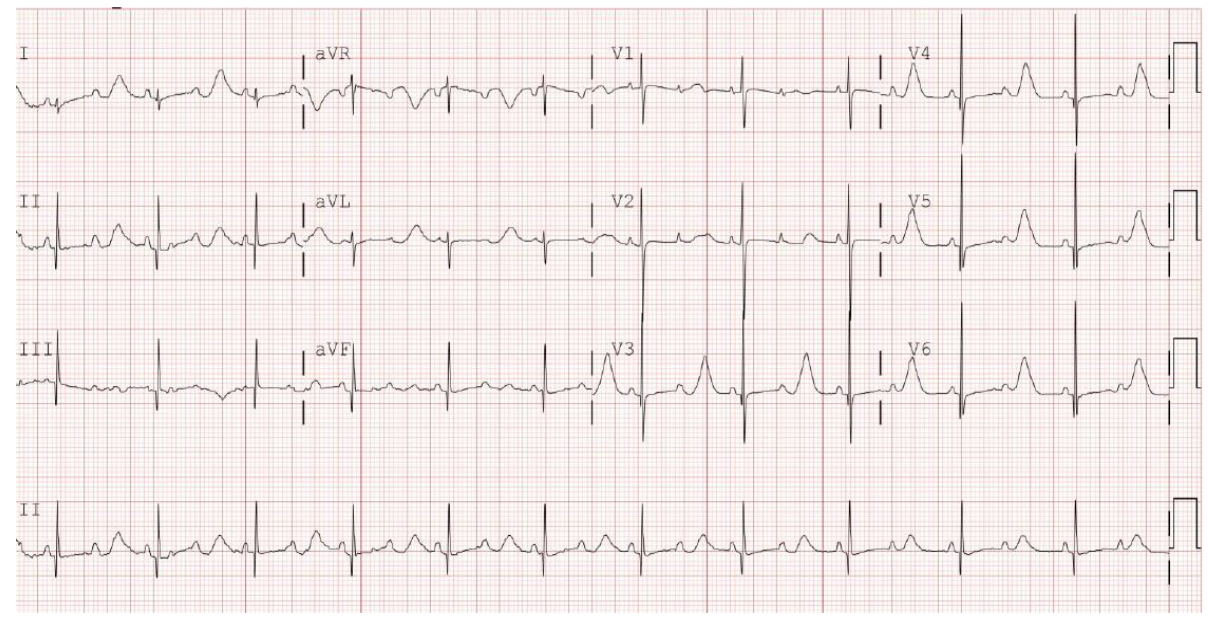

Figure 2. Postnatal 12-lead electrocardiogram showed bradycardia. The heart rate was 68 beats/min with QT prolongation of a corrected QT interval (QTc) of $680 \mathrm{~ms}$ (using Bazett formula) and a pseudo 2:1 atrioventricular block. 
stered because of sustained prolongation of the QT interval and 2:1 AV block. The dose of mexiletine was gradually increased to $15 \mathrm{mg} / \mathrm{kg} /$ day. One week after mexiletine inception, the ECG still showed QT interval prolongation (QTc, $632 \mathrm{~ms}$ ), but no AV block was observed (Figure 3).

The baby's pedigree indicated no cardiac events or sudden death. ECG of the parents and older sister revealed a normal QT interval (QTc, 400 to $430 \mathrm{~ms}$ ). Genetic testing identified a heterozygous Gly402Ser (c.1204G>A) mutation in CACNA1C, confirm ing the diagnosis of LQT8. Familial genetic screening was rejected by her parents.

The baby was discharged on the 35th hospital day without complications, and continued oral propranolol and mexiletine. No life-threatening tachyarrhythmias were noted during a followup period of 13 months. The patient did not develop seizures or neurodevelopmental delays and dysmorphic features.

\section{DISCUSSION}

This is the first report describing congenital LQT8 characterized by fetal onset of bradycardia and 2:1 AV block, in Korea. Currently, LQTS is classified into 17 genotypes. Three major genes, namely, $K C N Q 1, K C N H 2$, and SCN5A (LQT1 through LQT3), are known to contribute to $75 \%$ of all cases. Efforts to explain the remaining heritability of LQTS resulted in the discovery of multiple minor LQTS genes, numbered LQT4 through LQT17 ${ }^{9}$. The minor LQTS genes collectively account for $5 \%$ to $10 \%$ cases $^{3)}$, while LQT8 accounts for $1 \%$ to $2 \%$ of all LQTS cases ${ }^{7}$.

Sinus bradycardia is the most common manifestation of fetal
LQTS $^{10)}$. Although most fetal arrhythmias are benign, some may cause sudden cardiac death. It is important to diagnose arrhythmia through prenatal examination to allow informed choice regarding delivery in a facility that can provide proper post-de livery treatment ${ }^{1)}$

Skinner et al. ${ }^{4)}$ summarized the treatment for LQTS based on severity. Long-acting beta blockers are recommended as the first treatment for all types of LQTS. Left sympathetic denervation has been shown to reduce the occurrence of ventricular tachyarrhy thmias in high-risk LQTS. Implanted defibrillators are reserved for those who have a cardiac arrest. Despite continued treatment, life-threatening tachyarrhythmias and sudden cardiac death occurred in many pediatric patients ${ }^{10,11}$. Fortunately, our patient had a stable cardiovascular state. Hence, we considered initiating medical treatment. There were no life-threatening tachyarrhy thmias during the follow-up period.

As shown in Figure 2, the ECG revealed extreme QT prolongation (QTc $680 \mathrm{~ms}$ ) associated with 2:1 AV block. However, PP intervals (440 ms) were much shorter than the prolonged QT interval. If the ventricular refractory period is extremely prolong ed, more than the sinus rate, it may present as a pseudo 2:1 AV block. The pseudo 2:1 AV block appears to be unique to congenital LQTS ${ }^{12)}$. LQTS with 2:1 AV block poses a high risk of sudden cardiac death $^{2)}$.

Mazzanti et al. ${ }^{13)}$ and Okuwaki et al. ${ }^{14)}$ reported mexiletine to be effective in LQT3 with 2:1 AV block. Mexiletine has the potential to shorten the QT interval by inhibiting the late sodium current. We considered that the administration of oral mexiletine could be helpful in our case, and 1:1 AV conduction was recovered.

In this case, LQT8 was diagnosed with genetic DNA sequencing,

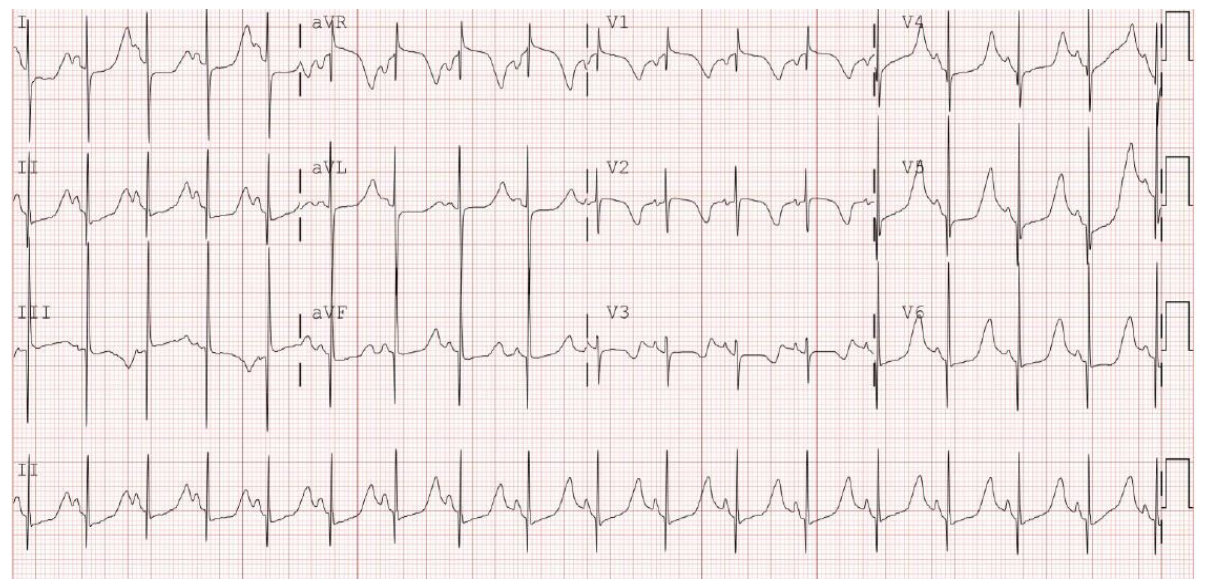

Figure 3. Electrocardiogram continued to show QT interval prolongation (QTc $632 \mathrm{~ms}$ ) but revealed no atrioventricular block after persistent mexiletine administration. 
as genetic analysis suggested an arrhythmia phenotype and consequent clinical outcomes ${ }^{9)}$. The $C A C N A 1 C$ gene encodes the core al subunit of the voltage-gated L-type calcium channel. In 2004, a CACNA1C mutation was reported in the first description of TS. TS is a rare genetic disorder accompanied by cardiac phenotypes, including QT prolongation, congenital heart dis ease, and extracardiac phenotypes, such as syndactyly, facial dysmorphism, seizure, and developmental delay ${ }^{5)}$. Since then, additional $C A C N A 1 C$ variants have been reported in patients with non-syndromic LQTS, referred to as LQT8 ${ }^{7}$. Our patient did not have any other TS characteristics during the follow-up period. This confirmed the diagnosis of LQT8.

In conclusion, LQTS is highlighted by the fact that it contributes to sudden cardiac death. Delivery should be performed in a center with adequate facilities, and prompt treatments should be adopted to prevent life-threatening arrhythmia after birth ${ }^{1,2)}$. To improve the outcome in such cases, an effort to provide more attention to fetal arrhythmia is imperative. Moreover, recent advances in genetic analyses can provide additional information regarding the arrhythmia phenotype and clinical outcomes ${ }^{9)}$.

\section{ARTICLE INFORMATION}

\section{Ethical statement}

This study was approved by the Institutional Review Board (IRB) of the Pusan National University Yangsan Hospital (appro val number: 05-2020-204). Written informed consent by the patients was waived due to a retrospective nature of our study.

\section{Conflicts of interest}

No potential conflict of interest relevant to this article was reported.

\section{Author contributions}

Conception or design: D.J., H.D.L., J.H.B.

Acquisition, analysis, or interpretation of data: D.J., T.K., J.H.B.

Drafting the work or revising: D.J., H.K., J.H.B.

Final approval of the manuscript: H.D.L., J.H.B.

\section{ORCID}

Donghoon Joo https://orcid.org/0000-0002-9411-1603

Joung-Hee Byun https://orcid.org/0000-0003-2088-4029

\section{Acknowledgments}

None

\section{REFERENCES}

1. Maeno Y, Hirose A, Kanbe T, Hori D. Fetal arrhythmia: prenatal diagnosis and perinatal management. J Obstet Gynaecol Res 2009;35:623-9.

2. Anuwutnavin S, Wanitpongpan $\mathrm{P}$, Chungsomprasong P, Soong swang J, Srisantiroj N, Wataganara T. Fetal long QT syndrome manifested as atrioventricular block and ventricular tachycardia: a case report and a review of the literature. Pediatr Cardiol 2013; 34:1955-62.

3. Schwartz PJ, Ackerman MJ, George AL Jr, Wilde AAM. Impact of genetics on the clinical management of channelopathies. J Am Coll Cardiol 2013;62:169-80.

4. Skinner JR, Winbo A, Abrams D, Vohra J, Wilde AA. Channelopathies that lead to sudden cardiac death: clinical and genetic aspects. Heart Lung Circ 2019;28:22-30.

5. Splawski I, Timothy KW, Sharpe LM, Decher N, Kumar P, Bloise $\mathrm{R}$, et al. $\mathrm{Ca}(\mathrm{V}) 1.2$ calcium channel dysfunction causes a multisystem disorder including arrhythmia and autism. Cell 2004; 119:19-31.

6. Fukuyama M, Wang Q, Kato K, Ohno S, Ding WG, Toyoda F, et al. Long QT syndrome type 8: novel CACNA1C mutations causing QT prolongation and variant phenotypes. Europace 2014;16: 1828-37.

7. Wemhoner K, Friedrich C, Stallmeyer B, Coffey AJ, Grace A, Zumhagen $\mathrm{S}$, et al. Gain-of-function mutations in the calcium channel CACNA1C (Cav1.2) cause non-syndromic long-QT but not Timothy syndrome. J Mol Cell Cardiol 2015;80:186-95.

8. Fukuyama M, Ohno S, Ozawa J, Kato K, Makiyama T, Nakagawa $\mathrm{Y}$, et al. High prevalence of late-appearing T-wave in patients with long QT syndrome type 8. Circ J 2020;84:559-68.

9. Adler A, Novelli V, Amin AS, Abiusi E, Care M, Nannenberg EA, et al. An international, multicentered, evidence-based reappraisal of genes reported to cause congenital long QT syndrome. Circulation 2020;141:418-28.

10. Cuneo BF, Etheridge SP, Horigome H, Sallee D, Moon-Grady A, Weng HY, et al. Arrhythmia phenotype during fetal life suggests long-QT syndrome genotype: risk stratification of perinatal longQT syndrome. Circ Arrhythm Electrophysiol 2013;6:946-51.

11. Dufendach KA, Timothy K, Ackerman MJ, Blevins B, Pflaumer A, Etheridge S, et al. Clinical outcomes and modes of death in timothy syndrome: a multicenter international study of a rare disorder. JACC Clin Electrophysiol 2018;4:459-66.

12. Rosenbaum MB, Acunzo RS. Pseudo 2:1 atrioventricular block and T wave alternans in the long QT syndromes. J Am Coll Car- 
diol 1991;18:1363-6.

13. Mazzanti A, Maragna R, Faragli A, Monteforte N, Bloise R, Memmi M, et al. Gene-specific therapy with mexiletine reduces arrhythmic events in patients with long QT syndrome type 3. J Am Coll Cardiol 2016;67:1053-8.
14. Okuwaki H, Kato Y, Lin L, Nozaki Y, Takahashi-Igari M, Horigome $\mathrm{H}$. Mexiletine infusion challenge test for neonatal long QT syndrome with 2:1 atrioventricular block. J Arrhythm 2019;35: 685-8. 